\title{
Direitos Humanos e Meio Ambiente: a nova dimensão da responsabilidade na sociedade de risco
}

\section{Human Rights and Environment: the new dimension of responsibility in the risk society}

\author{
Tiago Martinez ${ }^{1}$ \\ Marcello Raposo Ciotola ${ }^{2}$
}

\begin{abstract}
RESUMO
As chamas que se alastraram pela Floresta Amazônica no segundo semestre de 2019 vieram acompanhadas de uma vasta gama de discussões sobre ética, direitos humanos e meio ambiente. No contexto caracterizado pelo risco e por políticas ambientais controversas, direcionar um olhar crítico para os problemas decorrentes dos discursos e práticas do governo brasileiro é indispensável. Assim, objetiva-se com essa investigação, apontar as questões que a política ambiental adotada suscita no âmbito dos direitos humanos e para a teoria ética da responsabilidade. Através de uma metodologia baseada em pesquisa bibliográfica, em notícias de sites da internet e em levantamento de dados estatísticos produzidos por institutos especializados, conclui-se que os direitos humanos não são apenas direitos propriamente ditos, mas são processos de lutas constantes pela vida digna, bem como que as ações humanas precisam considerar não apenas os seus efeitos a curto prazo, mas também as suas consequências para a continuidade da vida humana no futuro.
\end{abstract}

\section{PALAVRAS-CHAVE:}

Direitos Humanos. Meio Ambiente. Ética. Responsabilidade. Sociedade de risco.

\begin{abstract}
The flames that spread through the Amazon rainforest in the second half of 2019 were accompanied by a wide range of discussions on ethics, human rights and the environment. In the context characterized by risk and controversial environmental policies, directing a critical eye to the problems arising from the discourses and practices of the brazilian government is indispensable. Thus, the objective of this investigation is to point out the issues that the adopted environmental policy raises in the scope of human rights and the ethical theory of responsibility. Through a methodology based on bibliographic research, news from internet sites and survey of statistical data produced by specialized institutes, it is concluded that human rights are not only rights themselves, but are processes of constant struggles for a dignified life, as well as human actions need to consider not only their short-term effects, but also their consequences for the continuity of human life in the future.
\end{abstract}

\section{KEYWORDS:}

Human Rights. Environment. Ethics. Responsibility. Risk Society.

\footnotetext{
${ }^{1}$ Doutorando em Direito Público e Evolução Social pela Universidade Estácio de Sá (UNESA/RJ - Bolsista integral pela CAPES). Mestre em Direito Público e Evolução Social pela Universidade Estácio de Sá (UNESA/RJ - Bolsista integral pela CAPES). Bacharel em Direito pela Universidade Estácio de Sá (UNESA/RJ).

${ }^{2}$ Professor de Ética no Programa de Pós-graduação em Direito da Universidade Estácio de Sá. Professor de Filosofia do Direito na Pontifícia Universidade Católica do Rio de Janeiro e na Universidade do Estado do Rio de Janeiro. Doutor em Direito pela Pontifícia Universidade Católica do Rio de Janeiro.
} 


\section{INTRODUÇÃO}

A preocupação com o avanço das queimadas na Floresta Amazônica ultrapassou as fronteiras nacionais para se tornar um dos temas de maior interesse do mundo. Os desmatamentos e as queimadas, difundidos pelas mídias e pelas pesquisas científicas, vieram acompanhados de uma vasta gama de discussões sobre ética, direitos humanos e meio ambiente.

É no cenário caracterizado pelo risco e por políticas ambientais controversas, que a pesquisa se encontra inserida. Neste quadro, as perguntas que ficam são: O que os discursos e práticas do atual governo nos revelam sobre a política ambiental brasileira? Como ocorreu a evolução da relação existente entre meio ambiente e direitos humanos? O que fica demonstrado quando a atuação estatal não visa a garantia dos direitos humanos, no caso, o direito a um meio ambiente ecologicamente equilibrado? Por que as discussões sobre responsabilidade, meio ambiente e direitos humanos são ainda mais relevantes na sociedade de risco?

Para responder a essas perguntas, realiza-se uma análise dos discursos e práticas do governo liderado pelo Presidente da República Jair Bolsonaro. A partir deste exame, são apontadas as relações existentes entre a política ambiental adotada, os direitos humanos, os desmatamentos e as queimadas que ocorrem na Floresta Amazônica. Além disso, procura-se realizar um diálogo dessas questões com a teoria ética da responsabilidade.

Quanto ao primeiro item, enfoca-se no conceito de "direitos humanos como processo", elaborado por Joaquín Herrera Flores; na noção de "luta pelo direito", de Rudolf Von Jhering; e na ideia de "indignação", proposta por Stéphane Hessel. No que toca a questão da responsabilidade na sociedade de risco, adota-se como marco teórico o sociólogo alemão Ulrich Beck; o filósofo, também de origem germânica, Hans Jonas; e o sociólogo brasileiro Leonardo Boff.

Objetiva-se com essa investigação, esclarecer que os direitos humanos não são apenas direitos propriamente ditos, mas são processos de lutas constantes pela vida digna, assim como que as ações humanas precisam levar em consideração não apenas os seus efeitos a curto prazo, mas também as suas consequências para a continuidade da vida humana no futuro, isto é, o agir 
precisa ter em conta a nova dimensão da responsabilidade. Para tanto, a pesquisa se vale de uma metodologia baseada em pesquisa bibliográfica, em notícias de sites da internet e em levantamento de dados estatísticos produzidos por institutos especializados.

\section{OS DISCURSOS, AS PRÁticas, OS DIREITOS HUMANOS E A FLORESTA AMAZÔNICA}

As chamas que se alastraram pela Floresta Amazônica no início do segundo semestre de 2019 direcionaram a atenção mundial para a política ambiental brasileira. No mesmo contexto, foi possível observar que os discursos e práticas do atual Presidente da República e de seus ministros, se não deixam de forma evidente o posicionamento do governo frente as questões ambientais, no mínimo criam um cenário de insegurança e de fomento às práticas de desmatamento. ${ }^{3}$ Mas o que este quadro fático nos revela?

Os números do desmatamento ${ }^{4}$ e das queimadas ${ }^{5}$ divulgados pelo Instituto Nacional de Pesquisas Espaciais (Inpe), assim como as imagens que circularam nas mídias sociais e nos

\footnotetext{
${ }^{3}$ A área sob alerta de desmatamento na Amazônia nos meses de junho a agosto de 2019 teve alta de 203,5\% em relação ao mesmo período de 2018. Se analisado somente o mês de agosto nos dois anos, o aumento foi de $223 \%$. Os dados são do sistema Deter-B, do Instituto Nacional de Pesquisas Espaciais (Inpe). Os alertas diários emitidos por esse Sistema de Detecção de Desmatamento em Tempo Real (Deter) servem para embasar ações de fiscalização do Instituto Brasileiro do Meio Ambiente e dos Recursos Naturais Renováveis (Ibama). Vale apontar, ainda, que de junho a agosto de 2019 foram $4.892,4 \mathrm{~km}^{2}$ sob alerta, enquanto no mesmo período de 2018 foram $1.611,7 \mathrm{~km}^{2}$. INSTITUTO NACIONAL DE PESQUISAS ESPACIAIS. Plataforma Terrabrasilis - Deter. Disponível em: <http://terrabrasilis.dpi.inpe.br/>. Acesso em: 08 nov. 2019.

${ }^{4}$ Posteriormente, em 18 de novembro de 2019, o Inpe divulgou que a área desmatada na Amazônia foi de 9.762 $\mathrm{km}^{2}$ no período entre agosto de 2018 e julho de 2019. Trata-se de um aumento de 29,5\% em relação ao período anterior (agosto de 2017 a julho de 2018), que registrou $7.536 \mathrm{~km}^{2}$ de área desmatada. Os dados são do Projeto de Monitoramento do Desmatamento na Amazônia Legal por Satélite (Prodes), considerado o mais preciso para medir as taxas anuais. Ele é diferente do Sistema de Detecção de Desmatamento em Tempo Real (Deter), que mostra os alertas mensais e já sinalizava tendência de aumento. INSTITUTO NACIONAL DE PESQUISAS ESPACIAIS. Prodes - Amazônia. Disponível em: <http://www.obt.inpe.br/OBT/assuntos/programas/amazonia/prodes>. Acesso em: 18 nov. 2019.

${ }^{5}$ Segundo dados do Inpe, o número de focos de incêndio florestal aumentou $83 \%$ entre janeiro e agosto de 2019 na comparação com o mesmo período de 2018. Desde $1^{\circ}$ de janeiro até a 20 de agosto foram contabilizados 74.155 focos. É o número mais elevado desde que os registros começaram, em 2013. REVISTA EXAME. Inferno na floresta: o que sabemos sobre os incêndios na Amazônia. Disponível em: < https://exame.abril.com.br/brasil/inferno-na-floresta-o-que-sabemos-sobre-os-incendios-na-amazonia/>. Acesso em: 09 nov. 2019.
} 
veículos tradicionais de comunicação geraram inúmeras implicações e a presidência tratou de refutar as críticas recebidas e apresentar respostas alinhadas ao pensamento de seu eleitorado.

Após atrito público com o governo, o engenheiro e doutor em física pelo Massachusetts Institute of Tecnology (MIT), Ricardo Galvão, foi exonerado do Inpe, uma vez que, segundo Jair Bolsonaro, ele poderia estar "à serviço de uma ONG” e divulgando dados que não condizem com a verdade. ${ }^{6}$ Em um dado momento, Bolsonaro também insinuou que as ONGs estariam praticando ações criminosas, pois os repasses que essas organizações recebiam haviam sido suspensos. ${ }^{7}$

Já quando perguntado sobre a possibilidade de crescimento associado a preservação ambiental, o Presidente da República declarou que seria possível, e complementou a resposta da seguinte maneira: "É só você deixar de comer menos um pouquinho. Quando se fala em poluição ambiental, é só você fazer cocô dia sim, dia não que melhora bastante a nossa vida também, está certo?"8.

O Presidente da República também se envolveu em conflito com a Chanceler alemã Ângela Merkel, com o Presidente da França Emmanuel Macron e, ainda, com o Cacique Raoni. Diversas ofensas foram trocadas. Neste imbróglio, foi possível observar, desde ameaças de retirada de investimentos por parte dos europeus, até piadas sexistas sobre a aparência da primeira-dama francesa, e declarações que desprezam a própria Floresta Amazônica e que desdenham um Cacique caiapó de oitenta e nove anos mundialmente conhecido. ${ }^{9}$

\footnotetext{
${ }^{6}$ FOLHA DE SÃO PAULO. Bolsonaro critica diretor do Inpe por dados sobre desmatamento que 'prejudicam' nome do Brasil. Disponível em: < https://www1.folha.uol.com.br/ambiente/2019/07/bolsonarocritica-diretor-do-inpe-por-dados-sobre-desmatamento-que-prejudicam-nome-do-brasil.shtml>. Acesso em: 08 nov. 2019.

${ }^{7}$ PORTAL G1 DE NOTÍCIAS. Bolsonaro diz que ONGs podem estar por trás de queimadas na Amazônia para 'chamar atenção' contra o governo. Disponível em: <https://g1.globo.com/politica/noticia/2019/08/21/bolsonaro-diz-que-ongs-podem-estar-por-tras-de-queimadasna-amazonia-para-chamar-atencao-contra-o-governo.ghtml>. Acesso em: 08 nov. 2019.

${ }^{8}$ PORTAL G1 DE NOTÍCIAS. Bolsonaro sugere 'fazer cocô dia sim, dia não' para reduzir poluição ambiental. Disponível em: <https://g1.globo.com/politica/noticia/2019/08/09/bolsonaro-sugere-fazer-coco-diasim-dia-nao-para-reduzir-poluicao-ambiental.ghtml>. Acesso em: 08 nov. 2019.

${ }^{9} \mathrm{Na}$ data de $1^{\circ}$ de outubro de 2019, em um encontro com garimpeiros, Jair Bolsonaro afirmou que: "O interesse na Amazônia não é no índio nem na p... da árvore. É no minério. E o Raoni fala pela aldeia dele, fala como cidadão. Não fala por todos os índios, não. É outro que vive tomando champanhe em outros países por aí". FOLHA DE SÃO PAULO. 'Interesse na Amazônia não é no índio nem na p... da árvore', diz Bolsonaro. Disponível em: <https://www1.folha.uol.com.br/ambiente/2019/10/o-interesse-na-amazonia-nao-e-no-indio-nem-na-porra-daarvore-diz-bolsonaro.shtml>. Acesso em: 09 de nov. 2019.
} 
Mas não são apenas as manifestações do Presidente da República que geram polêmicas quando o assunto é meio ambiente. O Ministro das Relações Exteriores Ernesto Araújo negou em diversas oportunidades o aquecimento global ${ }^{10}$ e afirmou em seu Twitter que a crise ambiental seria "uma mentira da esquerda" para prejudicar o governo.

Já o Ministro do Meio Ambiente Eduardo Salles atribuiu ao tempo seco a intensificação das queimadas observadas na Amazônia. Entretanto, a nota técnica elaborada pelo Instituto de Pesquisa Ambiental da Amazônia (Ipam), publicada em agosto de 2019, contraria a versão do Ministro. De acordo com a pesquisa, "o período seco, por si só, não explica este aumento", visto que a estiagem observada em 2019 está mais branda do que aquelas observadas nos anos anteriores. O órgão indica que o desmatamento seria o principal responsável pela ocorrência de incêndios florestais. ${ }^{11}$

Vale destacar que os discursos e argumentos trazidos pelo governo carecem, na maior parte das vezes, de provas e de cientificidade, o que nos leva a questão da responsabilidade, esta que será discutida no próximo capítulo.

Mas por que essas falas e práticas são relevantes para a presente pesquisa? Segundo o relatório "Máfias do Ipê: como a violência e a impunidade impulsionam o desmatamento na Amazônia brasileira"12, formulado pela Human Rights Watch ${ }^{13}$, os grupos criminosos envolvidos em desmatamento ilegal assumiram os discursos do governo e as políticas de enfraquecimento do cumprimento da lei ambiental como um sinal verde para destruir a floresta, agravando, dessa maneira, os problemas ambientais presentes nos governos anteriores.

\footnotetext{
${ }^{10}$ Em uma reunião realizada no dia 3 de agosto de 2019 com os diplomatas da Secretaria de Assuntos de Soberania Nacional e Cidadania, o Ministro Ernesto Araújo utilizou um exemplo pessoal para provar o seu ponto: "Não acredito em aquecimento global. Vejam que fui a Roma em maio e estava tendo uma onda de frio enorme. Isso mostra como as teorias do aquecimento global estão erradas". REVISTA EXAME. Ernesto Araújo nega aquecimento global: 'Fui a Roma em maio e havia uma onda de frio'. Disponível em: <https://epoca.globo.com/guilherme-amado/ernesto-araujo-nega-aquecimento-global-fui-roma-em-maio-haviauma-onda-de-frio-23851347>. Acesso em: 09 nov. 2019.

11 INSTITUTO DE PESQUISA AMBIENTAL DA AMAZÔNIA. Nota técnica - Amazônia em chamas. Disponível em: < https://ipam.org.br/wp-content/uploads/2019/08/NT-Fogo-Amazo\%CC\%82nia-2019-1_2.pdf>. Acesso em: 10 nov. 2019. p.3.

12 HUMAN RIGHTS WATCH. Máfias do Ipê: como a violência e a impunidade impulsionam o desmatamento na Amazônia brasileira. Disponível em: <https://www.hrw.org/sites/default/files/report_pdf/brazil0919pt_web.pdf>. Acesso em: 10 nov. 2019.

${ }^{13}$ Organização internacional não-governamental que defende e realiza pesquisas sobre os direitos humanos. A sua sede está localizada na cidade de Nova York.
} 
O relatório também recorda atos e falas de Bolsonaro, como por exemplo, a ameaça de deixar o Acordo de Paris, a promessa de campanha de reduzir o número de áreas protegidas, a decisão de abrir as terras indígenas para exploração mineral, e as acusações de que as agências ambientais, como Ibama e ICMBio, são “indústrias de multas” que deveriam passar por uma reformulação.

Nas ações concretas do governo, o relatório da Human Rigths Watch assinala que o orçamento discricionário do Ministério do Meio Ambiente foi reduzido em 23\%, eliminando, assim, parcela significativa dos recursos destinados à fiscalização e ao combate a incêndios na Amazônia. O governo também congelou a demarcação de terras indígenas ${ }^{14} \mathrm{e}$ de áreas de proteção ambiental, bem como o número de multas relacionadas ao desmatamento em todo o país, aplicadas pelo IBAMA, foram reduzidas em 37\% em comparação com o ano de 2018. Além disso, o atual governo ainda extinguiu o Departamento de Florestas do Ministério do Meio Ambiente ${ }^{15}$, este que era um dos setores responsáveis por planejar as grandes operações de combate ao desmatamento através da integração com as agências federais.

Desse modo, o que se percebe é que a atual política ambiental brasileira favorece a degradação do meio ambiente e, por conseguinte, a violação dos direitos humanos. Mas, como ocorreu a evolução da relação existente entre meio ambiente e direitos humanos? O que os discursos e práticas do governo nos revelam sobre os direitos humanos?

Há décadas que a proteção aos direitos humanos e ao meio ambiente ecologicamente equilibrado permeiam as discussões tanto em âmbito nacional como internacional. É fato que a Declaração Universal dos Direitos Humanos de 1948 reconheceu em esfera universal os valores supremos da liberdade, igualdade e fraternidade entre os homens, porém, como toda e qualquer declaração, está vinculada ao tempo histórico em que foi redigida. Verifica-se que, apesar de sua relevância, ela se limitou às necessidades mais iminentes da época, quais sejam, os direitos civis, políticos, econômicos e culturais. ${ }^{16}$

\footnotetext{
${ }^{14}$ HUMAN RIGHTS WATCH, op. cit., p.47.

15 Ibidem, p.127.

${ }^{16}$ VAL, Eduardo Manuel. A Declaração Universal dos Direitos Humanos e seu Espelho: a Declaração Americana de Direitos Humanos e seus Reflexos no Constitucionalismo na América Latina. In: Carol Proner; Héctor Olasolo; Carlos Villán Durán; Gisele Ricobom; Charlotth Back. (Orgs.). 70 Aniversario de la Declaración Universal de Derechos Humanos: Protección Internacional de los Derechos Humanos en cuestión. Valencia: Tirant lto Blanch, 2018, p.174. O professor Eduardo Manuel Val esclarece que declaração fixou vinte e nove direitos políticos, civis,
} 
No entanto, a complexidade social resultante das guerras, das invenções científicas, dos flagelos negativos da mutilação humana, da degradação ambiental e da competição econômica, demandou pelo surgimento de novos direitos, estes que foram intitulados de transindividuais, difusos e coletivos. Tais direitos compreendem não apenas a subjetividade, mas também a pluralidade, o respeito, a solidariedade, a defesa da paz, do meio ambiente equilibrado e dos bens que fazem parte do patrimônio comum da humanidade. ${ }^{17}$

Diante deste panorama, foi elaborada, em 1972, a Declaração de Estocolmo. ${ }^{18}$ Logo em seu primeiro princípio a declaração internacional aborda, ainda que de forma tímida, temas referentes aos direitos transindividuais, coletivos e difusos:

\begin{abstract}
Princípio 1 . O homem tem o direito fundamental à liberdade, à igualdade e ao desfrute de condições de vida adequadas em um meio ambiente de qualidade tal que lhe permita levar uma vida digna e gozar de bem-estar, tendo a solene obrigação de proteger e melhorar o meio ambiente para as gerações presentes e futuras. A este respeito, as políticas que promovem ou perpetuam o apartheid, a segregação racial, a discriminação, a opressão colonial e outras formas de opressão e de dominação estrangeira são condenadas e devem ser eliminadas. ${ }^{19}$
\end{abstract}

Observa-se, através do referido princípio, a vinculação da questão ambiental aos direitos humanos, como por exemplo, a liberdade e a igualdade. O dispositivo demonstra, essencialmente, que para se ter um meio ambiente ecologicamente equilibrado é indispensável a realização de um diálogo entre os princípios fundamentais de direitos humanos e o meio ambiente.

Assim, a Conferência de Estocolmo é o marco inicial do direito internacional onde a proteção ambiental é tratada como garantia do homem, isto é, como um direito humano. Após 1972, a busca pelo aperfeiçoamento das políticas ambientais e da efetivação da proteção ambiental como um direito humano prosseguiu, e diversas outras conferências, como a Eco-92

\footnotetext{
econômicos, sociais e culturais que serviram de "motor para impulsionar profundas reformas na sociedade internacional, incluídos os processos de descolonização".

${ }^{17}$ BOTELHO, Tiago Resende. O reconhecimento do meio ambiente ecologicamente equilibrado como direito humano e fundamental. In: XXII Encontro Nacional do CONPEDI. Direito Ambiental II. 1.ed. Curitiba: Unicuritiba, 2013. Disponível em: <http://www.publicadireito.com.br/artigos/?cod=ab73f542b6d60c4d>. Acesso em: 15 nov. 2019, p.308.

${ }^{18}$ A Conferência das Nações Unidas sobre o Meio Ambiente Humano, reunida em Estocolmo de 5 a 16 de junho de 1972, atenta à necessidade de um critério e de princípios comuns que ofereçam aos povos do mundo inspiração e guia para preservar e melhorar o meio ambiente humano.

${ }^{19}$ UNITED NATIONS. Report of the United Nations Conference on the Human Environment. Disponível em: <http://www.un-documents.net/aconf48-14r1.pdf>. Acesso em: 15 nov. 2019, p.3.
} 
(1992), a Rio+10 (2002), a Rio+20 (2012) e a Cúpula do Desenvolvimento Sustentável (2015), foram realizadas.

No Brasil, o núcleo essencial da tutela do meio ambiente encontra-se presente no artigo 225 do diploma pátrio vigente. ${ }^{20}$ É possível dizer, acompanhando as palavras de José Afonso da Silva, que a Constituição Federal de 1988 possui importância singular nesse contexto, uma vez que foi "a primeira a tratar deliberadamente da questão ambiental", sendo assim, "uma Constituição eminentemente ambientalista". ${ }^{21}$

Entender o meio ambiente equilibrado como um direito fundamental significa enxergar que uma natureza sadia é imprescindível para a criação e desenvolvimento de condições favoráveis a manutenção das formas de vida, assim como para a convivência dos seres humanos e para a promoção da autonomia, do bem-estar e da liberdade. Como bem aponta Délton Winter Carvalho:

(...) a partir da constatação de que a dignidade da pessoa humana encontra no meio ambiente ecologicamente equilibrado um pressuposto para uma vida saudável, desloca-se sua percepção fundada apenas sobre a pessoa (construção fundamentalmente decorrente da tradição humanista-individualista) para uma noção transindividual, consubstanciada no termo qualidade de vida. Ou seja, a dignidade da pessoa humana encontra-se condicionada à qualidade dos recursos ambientais e ecológicos, o que, por evidente, permitirá, por exemplo, uma vida humana saudável. Nesse sentido, pode ser assegurada a existência, no artigo 225 da CF/1988, de um princípio do meio ambiente ecologicamente equilibrado como um direito fundamental da pessoa humana. ${ }^{22}$

O direito a um meio ambiente ecologicamente equilibrado é, em síntese, indispensável para o atendimento de outro valor fundamental, que é o direito à vida das gerações presentes e futuras, pois, quando não equilibrado, todos os demais direitos do homem ficam ameaçados. ${ }^{23}$

\footnotetext{
20 “Art. 225. Todos têm direito ao meio ambiente ecologicamente equilibrado, bem de uso comum do povo e essencial à sadia qualidade de vida, impondo-se ao poder público e à coletividade o dever de defendê-lo e preserválo para as presentes e futuras gerações". BRASIL. Constituição da República Federativa do Brasil de 1988. Disponível em: <http://www.planalto.gov.br/ccivil_03/constituicao/constituicao.htm>. Acesso em: 15 nov. 2019. ${ }^{21}$ SILVA, José Afonso da. Direito Ambiental Constitucional. 4.ed. São Paulo: Malheiros, 2003, p.46.

${ }^{22}$ CARVALHO, Délton Winter de. A sociedade do risco global e o meio ambiente como um direito personalístico intergeracional. In: Revista de Direito Ambiental. Ano 13, n.52, out-dez. /2008. São Paulo: Revista dos Tribunais, 2008, p.30.

23 Destaca-se que, embora o direito ao meio ambiente ecologicamente equilibrado não esteja expressamente previsto no rol dos direitos e garantias fundamentais, isto não lhe retira o caráter de direito fundamental. $\mathrm{O}$ artigo $5^{\circ}, \S^{\circ}$, da Constituição Federal de 1988, apresenta um conceito aberto de direitos fundamentais, não os limitando ao Título II, mas sim estendendo-os a outros que decorrem do regime e dos princípios adotados pela Constituição ou, ainda, dos tratados internacionais de direitos humanos dos quais o Brasil faça parte.
} 
Portanto, conclui-se, a partir da leitura do artigo 225 da Constituição Federal, que o meio ambiente ecologicamente equilibrado é um direito humano e fundamental de terceira dimensão, ligado ao valor solidariedade e fraternidade. Ademais, por ser um bem essencial à vida digna, isto é, uma extensão do direito à vida, à liberdade, à igualdade, à segurança e à propriedade, deve-se reservar uma atenção especial no que diz respeito à sua proteção e preservação. ${ }^{24}$

Ressalte-se, ainda, que o meio ambiente possui um caráter dúplice, visto que, simultaneamente, se consolida como um direito subjetivo, incidindo sobre todo o grupo social, tanto em âmbito nacional como internacional, o dever de preservar o meio ambiente equilibrado, bem como se configura como um direito objetivo pelo qual o Estado, mediante ações preventivas, restauradoras e promocionais, possui o dever de assegurar a todos a satisfação do direito ao meio ambiente ecologicamente equilibrado. Logo, a sua defesa deve ser realizada não apenas pelo poder público, mas também promovida pela coletividade.

Entretanto, é evidente que apesar de o Estado não ser o único responsável em tutelar o bem ambiental, ele é o agente que possui o maior poderio em garantir a proteção desse bem. Mas o que acontece quando o governo adota discursos e ações contrárias à Constituição, às declarações e aos tratados ${ }^{25}$ internacionais dos quais é signatário? O que fica demonstrado quando a atuação estatal não visa a garantia dos direitos humanos, no caso, o direito a um meio ambiente ecologicamente equilibrado?

O que se verifica é que as proposições elaboradas pelo filósofo espanhol Joaquín Herrera Flores, em sua obra intitulada A (re) invenção dos Direitos Humanos, estão corretas. De acordo com o autor, vivemos em um contexto social, econômico, político e cultural onde o mercado impõe regras aos Estados através de instituições globais. Um mercado que se declara

\footnotetext{
${ }^{24}$ BOTELHO, Tiago Resende. op.cit., p.328.

${ }^{25}$ Vale apontar que o Brasil faz parte da Organização do Tratado de Cooperação Amazônica (OTCA), bloco socioambiental formado pelos Estados que partilham o território Amazônico. As origens da organização remontam a 1978, quando, por iniciativa brasileira, os oito países amazônicos assinaram, em Brasília, o Tratado de Cooperação Amazônica (TCA), com o objetivo promover o desenvolvimento integral da região e o bem-estar de suas populações, além de reforçar a soberania dos países sobre seus territórios amazônicos. O fortalecimento da cooperação regional seria o principal meio para alcançar esses objetivos. BRASIL. Organização do Tratado de Cooperação Amazônica (OTCA). Disponível em: <http://www.itamaraty.gov.br/pt-BR/politicaexterna/integracao-regional/691-organizacao-do-tratado-de-cooperacao-amazonica-otca>. Acesso em: $3 \mathrm{dez}$. 2019.
} 
"falaciosamente como livre" e faz com que os direitos sejam encarados como "custos sociais das empresas, que devem suprimi-los em nome da competividade". ${ }^{26}$

O filósofo espanhol sustenta que os direitos humanos não são direitos conquistados de uma vez por todas. Os direitos não são apenas uma plataforma para se obter mais direitos. "Os direitos humanos, mais que direitos 'propriamente ditos', são processos; ou seja, o resultado sempre provisório das lutas que os seres humanos colocam em prática para ter acesso aos bens necessários para a vida". ${ }^{27}$

Os direitos somente são alcançados após um processo de lutas pelo acesso aos bens exigíveis para se viver com dignidade, a saber: a liberdade de expressão, a convicção religiosa, educação, moradia, trabalho, meio ambiente, cidadania, entre outros. Em algumas ocasiões essas lutas se respaldam em estruturas de garantias já formalizadas (hipótese em que a luta jurídica se encontra aliada à luta social), no entanto, em outros casos, as lutas não se apoiam em sistemas jurídicos e se desenvolvem na ilegalidade. É por esta razão que o ponto central da teoria do filósofo espanhol reside nos bens necessários para se viver de forma digna. As normas jurídicas resultantes das lutas possuem apenas um caráter instrumental e servem para garantir o acesso a tais bens. ${ }^{28}$

Desse modo, para Joaquín Herrera Flores:

(...) quando falamos de direitos humanos, falamos de dinâmicas sociais que tendem a construir condições materiais e imateriais necessárias para conseguir determinados objetivos genéricos que estão fora do direito (os quais, se temos a suficiente correlação de forças parlamentares, veremos garantidos em normas jurídicas). Quer dizer, ao lutar por ter acesso aos bens, os atores e atrizes sociais que se comprometem com os direitos humanos colocam em funcionamento práticas sociais dirigidas a nos dotar, todas e todos, de meios e instrumentos - políticos, sociais, econômicos, culturais ou jurídicos - que nos possibilitem construir as condições materiais e imateriais necessárias para poder viver. ${ }^{29}$

Prosseguindo em sua teoria, Herrera Flores questiona: "Por que lutamos pelos direitos?" Como resposta, o autor defende que os processos de luta ocorrem porque precisamos ter acesso aos bens exigíveis para viver e "porque eles não caem do céu, nem vão correr pelos rios de mel

\footnotetext{
${ }^{26}$ FLORES, Joaquín Herrera. A (re) invenção dos Direitos Humanos. Tradução: Carlos Roberto Diogo Garcia; Antonio Henrique Graciano; Jeferson Aparecido Dias. Florianópolis: Fundação Boiteux, 2009, pp.30-31.

${ }^{27}$ Ibidem, p.34.

${ }^{28}$ Ibidem, pp.34-35.

${ }^{29}$ Ibidem, p.35.
} 
de algum paraíso terrestre". ${ }^{30}$ Então, o acesso aos bens está inserido em um processo complexo, onde uns possuem mais facilidade para obtê-los, enquanto outros talvez sequer tenham a possibilidade de alcançá-los. A luta pelos direitos se inicia a partir do instante em que determinados indivíduos consideram injustos e desiguais os processos hegemônicos de divisão do fazer humano.

O objetivo das lutas e das práticas e dinâmicas sociais é o acesso igualitário e generalizado aos bens "que fazem com que a vida seja digna de ser vivida". A dignidade é um fim material, e não apenas um conceito ideal ou abstrato que emanou "de algum céu estrelado que paira transcendentalmente sobre nós". ${ }^{31}$ Além disso, conforme os argumentos levantados por Herrera Flores, os direitos humanos não são neutros, uma vez que não há neutralidade possível quando a finalidade é fortalecer os indivíduos e grupos que sofrem violações, fornecendo-os instrumentos para que possam buscar uma vida digna. ${ }^{32}$

Assim, o posicionamento do governo de Jair Bolsonaro nos revela algo importante para a teoria dos direitos humanos. Os avanços promovidos pelas conferências internacionais e pela Constituição não significam que os direitos humanos foram conquistados de uma vez por todas. A qualquer momento, os progressos alcançados, mesmo com toda a problemática envolvendo as realizações efetivas e práticas, podem ter a importância reduzida ou até mesmo serem violados e abandonados. Como se percebe, o conteúdo básico dos direitos humanos não é o direito a ter direitos, mas sim um conjunto de lutas constantes pela dignidade, cujos resultados, deverão ser garantidos por regras jurídicas, políticas públicas e "por uma economia aberta às exigências da dignidade". ${ }^{33}$

O jurista alemão Rudolf Von Jhering declarou em uma conferência realizada em Viena, no ano de 1872, que "todo direito no mundo foi adquirido pela luta". ${ }^{34}$ Para que os princípios que hoje vigoram no direito se materializassem, foi indispensável impô-los através da luta àqueles que não os aprovavam. Portanto, os direitos de um indivíduo ou de um povo dependem da disposição dos mesmos em defendê-los.

\footnotetext{
${ }^{30}$ Ibidem, p.36.

${ }^{31}$ Ibidem, p.37.

${ }^{32}$ Ibidem, p.38.

33 Ibidem, p.39.

34 JHERING, Rudolf Von. A luta pelo direito. Leme: CLEdijur, 2018, p.12.
} 
É a dor moral, causadora da sensação de injustiça, que leva os indivíduos a lutarem pelos direitos que consideram pertinentes. ${ }^{35}$ Há uma "voz interior", decorrente da personalidade, do sentimento pelo direito e da estima que deve a si mesmo, que não permite ao indivíduo retirarse da luta. ${ }^{36}$ A partir dessa leitura, a resistência à injustiça se configura como um dever do indivíduo para consigo mesmo, pois é um preceito da existência moral, bem como é um dever perante a sociedade, visto que o triunfo só é alcançado quando for geral. ${ }^{37}$

Um dos elementos centrais do sentimento de injustiça é o mesmo para Jhering ${ }^{38}$ e para o também alemão, posteriormente naturalizado francês, de origem judia, sobrevivente da $2^{\mathrm{a}}$ Guerra Mundial, e um dos membros da comissão responsável por elaborar o que veio a ser a Declaração Universal dos Direitos Humanos, Stéphane Hessel. O grau de energia despendido nas resistências e nas reações em face das violações aos direitos reside na indignação sentida pelas pessoas. É por esta razão que Hessel convoca à todos para que se indignem:

Eu desejo a todos, a cada um de vocês, que tenham seu motivo de indignação. Isto é precioso. Quando alguma coisa nos indigna, como fiquei indignado com o nazismo, nos transformamos em militantes; fortes e engajados, nos unimos à corrente da história, e a grande corrente da história prossegue graças a cada um de nós. Essa corrente vai em direção de mais justiça, de mais liberdade, mas não de uma liberdade descontrolada da raposa no galinheiro. Esses direitos, cujo programa a Declaração Universal redigiu em 1948, são universais. Se você encontrar alguém que não é beneficiado por eles, compadeça-se, ajude-o a conquistá-lo. ${ }^{39}$

Nesse sentido, caso se queira garantir o direito humano ao meio ambiente ecologicamente equilibrado e que permita uma existência digna, as lutas não podem ser cessadas. A indignação é, portanto, o passo inicial para o engajamento na luta pelos direitos e por uma sociedade mais justa, enquanto que a pior das atitudes é a indiferença, ou seja, dizer "não posso fazer nada" 40.41

\footnotetext{
${ }^{35}$ Ibidem, p.30. "A experiência, porém, nos ensina também que outros indivíduos colocados em semelhante situação tomam uma decisão inteiramente contrária; preferem a paz a um direito conquistado tão trabalhosa e penosamente (...). Consideramos este modo de ver que se encontra muitas vezes na vida, como perfeitamente condenável (...). Se fosse possível supor que chegasse alguma vez a prevalecer, destruir-se-ia o próprio direito, porque defende a fuga diante da injustiça, enquanto o direito não existe sem lutar contra ela".

${ }^{36}$ Ibidem, p.30.

${ }^{37}$ Ibidem, p.31.

${ }^{38}$ Ibidem, p.43. "A indignação que as diversas classes manifestam quando são atacadas em um dos direitos que formam a base da sua existência, reproduz-se também nos Estados quando se atacam as instituições que representam, o princípio especial que as faz viver (...)".

${ }^{39}$ HESSEL, Stéphane. Indignai-vos. Tradução: Marli Peres. São Paulo: Leya, 2011.

${ }^{40}$ Ibidem, p.22.

${ }^{41}$ Em 20 de novembro de 2019, o Presidente da República afirmou ser impossível acabar com o desmatamento e com as queimadas, pois seria um fenômeno "cultural". REUTERS BRASIL. Ministro promete reduzir
} 


\section{A NOVA DIMENSÃO DA RESPONSABILIDADE NA SOCIEDADE DE RISCO}

As discussões sobre o meio ambiente e os direitos humanos assumem uma relevância ainda maior em uma conjuntura marcada pelos riscos. Segundo o sociólogo alemão Ulrich Beck, na modernidade tardia, a produção social de riquezas está atrelada a produção social de riscos. No decorrer do processo de modernização, as forças produtivas cresceram de forma exponencial, ocasionando riscos e "potenciais de autoameaça numa medida até então desconhecida". ${ }^{2}$

É verdade que os riscos não são uma novidade. Cristóvão Colombo, por exemplo, quando saiu em busca de novas terras e continentes assumiu riscos. Estes riscos, no entanto, eram restritos a um determinado número de pessoas, e não situações de ameaça global, como as que aparecem para a humanidade com a fissão nuclear ou com o acúmulo de lixo nuclear. Conforme Beck, o termo "risco" tinha, no contexto da época, "um tom de ousadia e aventura, e não o da possível autodestruição da vida na Terra". ${ }^{43}$

As florestas também são desmatadas há séculos, porém, o desmatamento contemporâneo ocorre em escala global, como consequência implícita da industrialização, gerando problemas sociais e políticos inteiramente diversos. Países como Noruega e Suécia, com ampla cobertura florestal e poucas indústrias poluentes, sofrem com a extinção de animais e plantas em razão da emissão de poluentes de outros países industrializados. Para o sociólogo alemão:

É de se notar, porém, que as ameaças de então, à diferença das atuais, agastavam somente o nariz ou os olhos, sendo, portanto, sensorialmente perceptíveis, enquanto os riscos civilizatórios atuais tipicamente escapam à percepção, fincando pé sobretudo na esfera das fórmulas físico-químicas (...). Os riscos e ameaças atuais diferenciamse, portanto, de seus equivalentes medievais, com frequência semelhantes por fora, fundamentalmente por conta da globalidade de seu alcance (ser humano, fauna, flora) e de suas causas modernas. São riscos da modernização. São um produto de série do maquinário industrial do progresso, sendo sistematicamente agravados com seu desenvolvimento ulterior. ${ }^{44}$

\footnotetext{
desmatamento, mas não apresenta meta. Disponível em: <https://br.reuters.com/article/domesticNews/idBRKBN1XU2F3-OBRDN>. Acesso em: 20 nov. 2019.

${ }^{42}$ BECK, Ulrich. Sociedade de Risco: rumo a uma outra modernidade. $2^{\mathrm{a}}$ ed. Tradução: Sebastião Nascimento. São Paulo: Editora 34, 2011, p.23.

${ }^{43}$ Ibidem, p. 25.

${ }^{44}$ Ibidem, p. 26.
} 
Assim, os riscos da modernização possuem uma tendência inerente à globalização. A produção industrial é acompanhada por um "universalismo das ameaças, independente dos lugares onde são produzidas". ${ }^{45} \mathrm{Nem}$ os ricos estão seguros diante dos riscos que eles próprios provocam e com os quais lucram. Este é o chamado "efeito bumerangue", termo utilizado por Beck para definir os efeitos colaterais da distribuição dos riscos. ${ }^{46}$

A urgência dos perigos ambientais aponta para a necessidade da adoção de uma outra postura e apresenta uma série de novos desafios à democracia. Sob o quadro do perigo iminente, as competências de atuação e as responsabilidades precisam ser redefinidas, uma vez que os danos causados à natureza se convertem em ameaças globais para as pessoas, em termos políticos, econômicos e culturais. Como esclarece Ulrich Beck, os "problemas ambientais não são problemas do meio ambiente, mas problemas completamente - na origem e nos resultados - sociais, problemas do ser humano, de sua história" e da sua relação com o mundo e com a realidade. ${ }^{47}$

O filósofo alemão Hans Jonas, em sua obra $O$ princípio responsabilidade, desenvolve suas ideias nessa mesma conjuntura de riscos. Para o autor, as técnicas modernas modificaram as ações humanas de tal maneira, com novos objetos e consequências, que a moldura da ética antiga não é mais capaz de enquadrá-las. A vulnerabilidade da natureza na contemporaneidade demonstra que nada menos do que a biosfera de todo o planeta passou a fazer parte daquilo pelo qual devemos ser responsáveis, visto que detemos o poder sobre ela. A natureza como responsabilidade do ser humano é, certamente, uma questão a partir da qual uma nova teoria ética deve ser pensada. ${ }^{48}$

Isto porque as teorias éticas anteriores não consideravam a condição global da vida humana e o futuro da existência da espécie. Contudo, diante da magnitude dos riscos, uma nova concepção de direitos e deveres se faz necessária. Os fundamentos de uma ética para a civilização tecnológica devem buscar não apenas o bem humano, "mas também das coisas extra-humanas, isto é, ampliar o reconhecimento de 'fins em si' para além da esfera do humano e incluir o cuidado com estes no conceito de bem humano". ${ }^{49}$

\footnotetext{
45 Ibidem, p.43.

46 Ibidem, p.44.

${ }^{47}$ Ibidem, pp.96-99.

48 JONAS, Hans. O princípio responsabilidade: ensaio de uma ética para a civilização tecnológica. Tradução: Marijane Lisboa e Luiz Barros Montez. Rio de Janeiro: Contraponto: PUC-RIO, 2006, p.39.

${ }^{49}$ Ibidem, p.41.
} 
Hans Jonas afirma que o imperativo apropriado para a nova forma de agir humana seria o seguinte: "Aja de modo a que os efeitos da tua ação sejam compatíveis com a permanência de uma autêntica vida humana sobre a Terra". O imperativo elaborado por Jonas sustenta que o indivíduo pode arriscar a sua própria vida, mas não a da humanidade, ou seja, nós não temos o direito de optar pela não existência das gerações futuras em razão da existência atual, ou até de as colocar em situação de risco. ${ }^{50}$

Enquanto que o imperativo categórico kantiano ${ }^{51}$ era direcionado ao indivíduo e ao momento, o imperativo categórico de Hans Jonas se preocupa não apenas com a coerência do ato consigo mesmo, mas com os seus efeitos para a continuidade da vida humana no futuro. Há um acréscimo da questão temporal que não está presente no pensamento lógico e instantâneo de Kant. Portanto, o imperativo categórico de Hans Jonas direciona um olhar atento a um futuro previsível e concreto, que "constitui a dimensão inacabada de nossa responsabilidade". 52

O aumento do poder de agir humano na sociedade de risco faz as ações irresponsáveis serem ainda mais perigosas, especialmente quando, por circunstâncias ou convenções, um indivíduo ou uma determinada coletividade possui sob os seus cuidados o bem-estar, o interesse ou destino de outras pessoas. $\mathrm{O}$ controle e o poder que aqueles possuem sobre estes, incluem as obrigações e os deveres. Assim, o exercício do poder sem a observação do dever é, dessa maneira, irresponsável, visto que significa uma ruptura da relação de confiança presente na responsabilidade. ${ }^{53}$

\section{Conforme Hans Jonas:}

Uma desigualdade de atribuições ou competências faz parte dessa relação. O capitão, senhor do navio e dos seus passageiros, assume responsabilidade por eles. $\mathrm{O}$ milionário entre os passageiros, que por acaso é o acionista principal da companhia marítima e que pode contratar ou demitir o capitão, concentra em si mais poder, mas não naquela situação. $\mathrm{O}$ capitão se comportaria de forma irresponsável caso, obedecendo ao seu superior, agisse de forma contrária ao seu entendimento, por exemplo, buscando bater um recorde de velocidade, embora em outra relação (aquela de empregado) ele tenha de 'responder' por seus atos, podendo ser recompensado por sua irresponsabilidade obediente ou punido por sua responsabilidade desobediente. Naquelas circunstâncias, ele é o superior e, por isso, deve assumir a responsabilidade. ${ }^{54}$

\footnotetext{
${ }^{50}$ Ibidem, p.47.

${ }^{51}$ KANT, Immanuel. Fundamentação da metafísica dos costumes. Tradução: Paulo Quintela. Lisboa: Edições 70, 2009, p.34. Segundo o filósofo de Königsberg: “(...) devo proceder sempre de maneira que eu possa querer também que a minha máxima se torne uma lei universal".

52 JONAS, Hans. op.cit., p.49.

${ }^{53}$ Ibidem, p. 168.

${ }^{54}$ Ibidem, p.169.
} 
São por estas razões que o presente trabalho acadêmico tece críticas à atual política ambiental brasileira. Os discursos e práticas do Presidente da República ${ }^{55}$ e de seus ministros parecem não compreender a nova expansão da responsabilidade sobre a biosfera e a sobrevivência da humanidade, que é resultado da extensão do poder sobre as coisas e do fato de que este seja, essencialmente, um poder destrutivo.

Negar os fatos comprovados pela ciência, empregar discursos e práticas sem medir as consequências $^{56}$, ou, ainda, se limitar às responsabilidades de seu próprio território ${ }^{57}$, sobretudo em um contexto de globalização, seja por interesses econômicos, políticos, sociais e ideológicos, significa adotar um "pensamento simplificador da realidade"58 e uma postura irresponsável perante os direitos e o futuro da humanidade.

Como bem ressalta o sociólogo brasileiro Leonardo Boff, devemos desenvolver um "sentimento de interdependência global”, pois é notório que todos dependem globalmente de todos, "que ninguém é uma estrela solitária e que no universo e na natureza tudo tem a ver com tudo em todos os momentos e em todas as circunstâncias". Ademais, tão relevante quanto a noção de interdependência é o conceito de "responsabilidade universal", isto é, deve-se analisar

\footnotetext{
${ }^{55}$ No dia 27 de novembro de 2019, duas entidades de direitos humanos apresentaram uma representação contra o presidente Jair Bolsonaro perante o Tribunal Penal Internacional (TPI), corte localizada em Haia, na Holanda, solicitando uma "investigação preliminar" das ações do presidente por "incitação ao genocídio e ataques sistemáticos contra populações indígenas". Para Belisário dos Santos Jr, advogado da Comissão Arns, "o avanço ilegal de madeireiros e garimpeiros (em áreas indígenas) ocorre porque a política oficial não é de proteção". BBC NEWS. O que diz a queixa apresentada contra Bolsonaro no Tribunal Penal Internacional. Disponível em: <https://www.bbc.com/portuguese/brasil-50595551>. Acesso em: 29 nov. 2019.

${ }^{56}$ Até o ator hollywoodiano Leonardo DiCaprio foi alvo de acusações sem provas. Em sua transmissão semanal via Facebook, o Presidente Jair Bolsonaro, no dia 29 de novembro de 2019, criticou o ator Leonardo DiCaprio por doar dinheiro a ONGs, estas que seriam as responsáveis pelas queimadas na Amazônia. Segundo o chefe do Executivo: "O que é mais fácil? 'Toca' fogo no mato. Tira foto, filma, manda para a ONG, a ONG divulga, entra em contato com o Leonardo DiCaprio e o Leonardo DiCaprio doa US\$ 500 mil para essa ONG. Leonardo DiCaprio, você está colaborando com as queimadas na Amazônia". THE NEW YORK TIMES. Brazil's President Criticizes DiCaprio Over Amazon Fires. Disponível em: <https://www.nytimes.com/aponline/2019/11/29/world/americas/ap-lt-brazil-amazon-dicaprio.html >. Acesso em: 30 nov. 2019.

${ }^{57}$ De acordo com Jair Bolsonaro, em discurso proferido na Assembleia Geral da ONU: "É falácia dizer que a Amazônia é patrimônio da humanidade (...). Questionaram aquilo que nos é mais sagrado: a nossa soberania". ONU NEWS. Veja na íntegra o discurso do presidente do Brasil nas Nações Unidas. Disponível em: < https://news.un.org/pt/story/2019/09/1688242>. Acesso em: 23 nov. 2019.

${ }^{58}$ MORIN, Edgar. Introdução ao Pensamento Complexo. $5^{\mathrm{a}}$ ed. Tradução do francês: Eliane Lisboa. Porto Alegre: Editora Sulina, 2015, pp.40-47. Termo utilizado pelo filósofo francês Edgar Morin para criticar as estruturas e as consequências do predomínio do pensamento cartesiano.
} 
os resultados benéficos e maléficos das políticas e intervenções que são feitas na natureza, visto que podem pôr fim ao frágil equilíbrio do planeta Terra. ${ }^{59}$

Por fim, "a visão da Terra como coisa e baú de recursos" precisa ser rejeitada. ${ }^{60} \mathrm{~A}$ extrema redução da biodiversidade, das águas, das florestas e da fertilidade dos solos evidencia que o atual modelo utilizado para habitar o planeta se tornou insustentável e coloca sob perigo o futuro da comunidade humana.

Nesse cenário, o agir responsável, não só dos agentes políticos, mas também da população em geral, é indispensável, dado que o direito humano ao meio ambiente ecologicamente equilibrado agasalha as gerações presentes e futuras, possuindo caráter intergeracional, ou seja, não dispensa a participação solidária e democrática da sociedade global, assim como não se pode ver restrito aos marcos soberanos das fronteiras nacionais estabelecidas pela racionalidade humana. Portanto, atinge um patamar intercomunitário e alcança toda a humanidade. ${ }^{61}$

\section{CONSIDERAÇÕES FINAIS}

Os discursos e práticas do atual governo brasileiro favorecem a degradação do meio ambiente e, consequentemente, a violação dos direitos humanos. O direito ao meio ambiente sadio, conforme demonstrado na pesquisa, deve ser entendido como um direito humano, visto que, em síntese, é indispensável para o atendimento de outro valor fundamental, que é o direito à vida das gerações presentes e futuras.

Quando a atuação estatal não visa a garantia dos direitos humanos, no caso, o direito a um meio ambiente ecologicamente equilibrado, chega-se à conclusão de que os direitos humanos não são direitos conquistados de uma vez por todas. A qualquer momento, os

\footnotetext{
${ }^{59}$ BOFF, Leonardo. Sustentabilidade: O que é - O que não é. 5.ed. rev. ampl. Petrópolis: Editora Vozes, 2016, p.16.

${ }^{60}$ Ibidem, p.73.

${ }^{61}$ BOTELHO, Tiago Resende. op.cit., p.27.
} 
progressos alcançados podem ter a importância reduzida ou até mesmo serem abandonados. Como se percebe, o conteúdo básico dos direitos humanos não é o direito a ter direitos, mas sim um conjunto de lutas constantes pela dignidade. Os direitos humanos não são apenas direitos propriamente ditos, são processos, e o passo inicial para transformar a realidade posta é a indignação.

Em uma conjuntura marcada pelos riscos, essa discussão se torna ainda mais relevante. Tendo em vista que os danos causados à natureza se convertem em ameaças globais para as pessoas, as competências de atuação e as responsabilidades precisam ser reformuladas. A responsabilidade humana sobre a natureza assume uma nova dimensão ética.

Isto porque, o desenvolvimento das tecnologias modificou as ações humanas de tal modo, dotando-as de um poder de transformação da realidade sem precedentes, que o agir precisa levar em consideração não apenas os seus efeitos a curto prazo, mas também as suas consequências para a continuidade da vida humana a longo prazo.

Assim, quando as ações humanas não compreendem essa nova expansão da responsabilidade, sobretudo quando, por certas circunstâncias, um indivíduo ou uma determinada coletividade possui sob os seus cuidados o bem-estar ou destino de outras pessoas, o que se evidencia é a irresponsabilidade e a violação de direitos.

\section{REFERÊNCIAS}

BBC NEWS. O que diz a queixa apresentada contra Bolsonaro no Tribunal Penal Internacional. Disponível em: <https://www.bbc.com/portuguese/brasil-50595551>. Acesso em: 29 nov. 2019.

BECK, Ulrich. Sociedade de Risco: rumo a uma outra modernidade. $2^{\mathrm{a}}$ ed. Tradução: Sebastião Nascimento. São Paulo: Editora 34, 2011.

BOFF, Leonardo. Sustentabilidade: O que é - O que não é. 5.ed. rev. ampl. Petrópolis: Editora Vozes, 2016. 
BOTELHO, Tiago Resende. O reconhecimento do meio ambiente ecologicamente equilibrado como direito humano e fundamental. In: XXII Encontro Nacional do CONPEDI. Direito Ambiental II. 1.ed. Curitiba: Unicuritiba, 2013. Disponível em: < http://www.publicadireito.com.br/artigos/?cod=ab73f542b6d60c4d>. Acesso em: 15 nov. 2019.

BRASIL. Constituição da República Federativa do Brasil de 1988. Disponível em: $<$ http://www.planalto.gov.br/ccivil_03/constituicao/constituicao.htm>. Acesso em: 15 nov. 2019.

Organização do Tratado de Cooperação Amazônica (OTCA). Disponível em: $<$ http://www.itamaraty.gov.br/pt-BR/politica-externa/integracao-regional/691-organizacaodo-tratado-de-cooperacao-amazonica-otca>. Acesso em: 3 dez. 2019.

CARVALHO, Délton Winter de. A sociedade do risco global e o meio ambiente como um direito personalístico intergeracional. In: Revista de Direito Ambiental. Ano 13, n.52, outdez. São Paulo: Revista dos Tribunais, 2008.

FLORES, Joaquín Herrera. A (re) invenção dos Direitos Humanos. Tradução: Carlos Roberto Diogo Garcia; Antonio Henrique Graciano; Jeferson Aparecido Dias. Florianópolis: Fundo São Boiteux, 2009.

FOLHA DE SÃO PAULO. Bolsonaro critica diretor do Inpe por dados sobre desmatamento que 'prejudicam' nome do Brasil. Disponível em: < https://www1.folha.uol.com.br/ambiente/2019/07/bolsonaro-critica-diretor-do-inpe-pordados-sobre-desmatamento-que-prejudicam-nome-do-brasil.shtml>. Acesso em: 08 nov. 2019.

'Interesse na Amazônia não é no índio nem na p... da árvore', diz Bolsonaro. Disponível em: <https://www1.folha.uol.com.br/ambiente/2019/10/o-interesse-na-amazonianao-e-no-indio-nem-na-porra-da-arvore-diz-bolsonaro.shtml>. Acesso em: 09 de nov. 2019.

HESSEL, Stéphane. Indignai-vos. Tradução: Marli Peres. São Paulo: Leya, 2011.

HUMAN RIGHTS WATCH. Máfias do Ipê: como a violência e a impunidade impulsionam o desmatamento na Amazônia brasileira. Disponível em: <https://www.hrw.org/sites/default/files/report_pdf/brazil0919pt_web.pdf>. Acesso em: 10 nov. 2019.

INSTITUTO DE PESQUISA AMBIENTAL DA AMAZÔNIA. Nota técnica - Amazônia em chamas. Disponível em: < https://ipam.org.br/wp-content/uploads/2019/08/NT-FogoAmazo\%CC\%82nia-2019-1_2.pdf>. Acesso em: 10 nov. 2019.

INSTITUTO NACIONAL DE PESQUISAS ESPACIAIS. Plataforma Terrabrasilis - Deter. Disponível em: <http://terrabrasilis.dpi.inpe.br/>. Acesso em: 08 nov. 2019.

Prodes - Amazônia. Disponível em: <http://www.obt.inpe.br/OBT/assuntos/programas/amazonia/prodes>. Acesso em: 18 nov. 2019. 
JHERING, Rudolf Von. A luta pelo direito. Leme: CLEdijur, 2018.

JONAS, Hans. O princípio responsabilidade: ensaio de uma ética para a civilização tecnológica. Tradução: Marijane Lisboa e Luiz Barros Montez. Rio de Janeiro: Contraponto: PUC-RIO, 2006.

KANT, Immanuel. Fundamentação da metafísica dos costumes. Tradução: Paulo Quintela. Lisboa: Edições 70, 2009

MORIN, Edgar. Introdução ao Pensamento Complexo. $5^{\text {a }}$ ed. Tradução do francês: Eliane Lisboa. Porto Alegre: Editora Sulina, 2015.

ONU NEWS. Veja na íntegra o discurso do presidente do Brasil nas Nações Unidas. Disponível em: < https://news.un.org/pt/story/2019/09/1688242>. Acesso em: 23 nov. 2019.

PORTAL G1 DE NOTÍCIAS. Bolsonaro sugere 'fazer cocô dia sim, dia não' para reduzir poluição ambiental. Disponível em: <https://g1.globo.com/politica/noticia/2019/08/09/bolsonaro-sugere-fazer-coco-dia-sim-dianao-para-reduzir-poluicao-ambiental.ghtml>. Acesso em: 08 nov.2019.

REUTERS BRASIL. Ministro promete reduzir desmatamento, mas não apresenta meta. Disponível em: <https://br.reuters.com/article/domesticNews/idBRKBN1XU2F3-OBRDN>. Acesso em: 20 nov. 2019.

REVISTA EXAME. Inferno na floresta: o que sabemos sobre os incêndios na Amazônia. Disponível em: < https://exame.abril.com.br/brasil/inferno-na-floresta-o-que-sabemos-sobreos-incendios-na-amazonia/>. Acesso em: 09 nov. 2019.

Ernesto Araújo nega aquecimento global: 'Fui a Roma em maio e havia uma onda de frio'. Disponível em: <https://epoca.globo.com/guilherme-amado/ernesto-araujonega-aquecimento-global-fui-roma-em-maio-havia-uma-onda-de-frio-23851347>. Acesso em: 09 nov. 2019.

SILVA, José Afonso da. Direito Ambiental Constitucional. 4.ed. São Paulo: Malheiros, 2003.

THE NEW YORK TIMES. Brazil's President Criticizes DiCaprio Over Amazon Fires. Disponível em: <https:/www.nytimes.com/aponline/2019/11/29/world/americas/ap-lt-brazilamazon-dicaprio.html>. Acesso em: 30 nov. 2019.

UNITED NATIONS. Report of the United Nations Conference on the Human Environment. Disponível em: <http://www.un-documents.net/aconf48-14r1.pdf〉. Acesso em: 15 nov. 2019.

VAL, Eduardo Manuel. A Declaração Universal dos Direitos Humanos e seu Espelho: a Declaração Americana de Direitos Humanos e seus Reflexos no Constitucionalismo na América Latina. In: Carol Proner; Héctor Olasolo; Carlos Villán Durán; Gisele Ricobom; Charlotth Back. (Orgs.). 70 ${ }^{\circ}$ Aniversario de la Declaración Universal de Derechos Humanos: Protección Internacional de los Derechos Humanos en cuestión. Valencia: Tirant lto Blanch, 
2018. Disponível em: <https://dialnet.unirioja.es/servlet/articulo?codigo=6850308>. Acesso em: 06 dez. 2019.

Data de Submissão: 07/12/2019

Data de Aceite: 16/12/2019 